\title{
DEVELOPMENT AND CHEMICAL CONSTITUTION OF A NUCLEAR BODY IN MICROSPOROCYTES OF BROMUS*
}

\author{
MARTA SHERMAN WALTERS \\ Santa Barbara Botanic Garden, Santa Barbara, California, U.S.A., and \\ Department of Biological Sciences, University of California, Santa Barbara
}

Received I1.vii.65

\section{INTRODUCTION}

A STRUCTURE, tentatively called a " nuclear body", has been observed in microsporocytes of a large number of species of Bromus (Walters, 1963). A single body appeared to be present in each microsporocyte. It was not found in shoot or root tips. With the usual acetocarmine technique, the nuclear body was first visible at zygotene or pachytene, at which time it was fully formed. Its origin and development during earlier stages was obscured by the chromosomes. The use of a technique developed by Rattenbury (1952), which stains the nuclear body without staining the chromosomes, has made it possible to observe its development in the earliest stages of meiosis.

The nuclear body could be an expression of metabolic activities characteristic of certain stages of meiosis. Therefore, certain cytochemical tests were undertaken to determine its components. The nuclear body is considered in relation to synthetic activities of chromosomes during the period of its origin, and the suggestion made that it probably arises from the chromosomes. It may correspond with structures such as puffs or " nebennucleoli " which have been attributed to synthetic activities of chromosomes at certain stages of division (Swift, I959; Brink, 1964).

\section{MATERIALS AND METHODS \\ (i) Developmental studies}

Two plants of Bromus arizonicus $(2 n=84)$ were used. Following methods described by Rattenbury (1952), spikelets were fixed for about 24 hours in a mixture of 2 parts 95 per cent. ethyl alcohol:I part 40 per cent. formalin +5 per cent. glacial acetic acid, and stored in 70 per cent. alcohol under refrigeration. Anthers were hydrolysed for 2 hours in $\mathrm{IN} \mathrm{HCl}$ at $60^{\circ} \mathrm{C}$. and then squashed in iron-acetocarmine.

\section{(ii) Cytochemical tests}

The materials used were $B$. arizonicus, carinatus $(2 n=56)$, marginatus $(2 n=56)$, maritimus $(2 n=56)$ and catharticus $(2 n=42)$. Except for catharticus (see below), material was fixed in a mixture of 3 parts absolute alcohol:I part glacial acetic acid for about 24 hours and stored in 70 per cent. alcohol under refrigeration.

* This investigation was supported in part by Research Grant GB-6og from the National Science Foundation and in part by Public Health Service Research Grant No. K3-GM-729 from the National Institute of General Medical Sciences. 
Cytochemical tests were made with whole P.M.C.'s or sectioned material. To facilitate spreading and flattening of whole P.M.C.'s, anthers were macerated in stomach liquid of the snail Helix aspersa diluted with 2 parts of distilled water for about 12 hours at $5^{\circ}$ C. (Faberge, 1945; Walters, 1963). Their contents were then spread in a small drop of 45 per cent. acetic acid on an albuminised slide and the anther wall debris removed. Mother cells thus became distributed in a single layer and were somewhat flattened by the weight of the cover slip. Cover slips were removed by the dry ice method of Conger and Fairchild (1953). Untreated cells and those treated with snail stomach fluid showed similar staining reactions with methyl green-pyronin, Azure B, and alloxan.

(a) Methyl green-pyronin. Methyl green and pyronin Y (from E. Gurr, Ltd.) were prepared as I per cent. aqueous solutions, and impurities were extracted with chloroform. P.M.C.'s were stained in a mixture of 5 parts pyronin : 3 parts methyl green.

(b) Azure B. Material was stained in a $0.25 \mathrm{mg} . / \mathrm{ml}$. solution of Azure $\mathrm{B}$ in $0 . \mathrm{I}$ $\mathrm{M}$ potassium buffer at $p \mathrm{H} 4.0$ at $40^{\circ} \mathrm{C}$. (Flax and Himes, 1952).

Ribonuclease. Experimental slides were treated with ribonuclease (Worthington, crystalline), $0.2 \mathrm{mg} . / \mathrm{ml}$. at $p \mathrm{H} 7.6$ and control slides with glass distilled water at $p \mathrm{H} 7.6$ for 2 hours at $37^{\circ} \mathrm{C}$. Both were stained with Azure B.

(c) Feulgen. Leuco-basic fuchsin was prepared as described by Darlington and La Cour ( 1962$)$. Whole anthers were hydrolysed for $5-40$ minutes in $1 \mathrm{~N} \mathrm{HCl}$ at $60^{\circ} \mathrm{C}$., stained for 2 hours, washed in $\mathrm{SO}_{2}$ water and then in distilled water, and squashed in 45 per cent. acetic acid. Also, slides with a single layer of P.M.C.'s from macerated anthers were hydrolysed, stained and washed as described above, transferred through an alcohol series and mounted in euparal.

(d) Alloxan. P.M.C.'s were treated with a solution of 1 per cent. alloxan in absolute alcohol at $37^{\circ}$ C. for $22-24$ hours and then in leuco-basic fuchsin for $3^{\circ}$ minutes (Yasuma and Ichikawa, 1953).

(e) Orange G-aniline blue. Anthers of catharticus were fixed in Lewitsky's solution and sections were stained in a mixture of $2 \mathrm{gm}$. orange $\mathrm{G}$ and $0.5 \mathrm{gm}$. aniline blue in roo ml. of $0.1 \mathrm{M}$ potassium citrate buffer at $\mathrm{pH}_{3}$ (La Cour et al., 1958).

\section{RESULTS}

Developmental studies of the nuclear body and observations of nucleoli were done by the method developed by Rattenbury (1952), which stains these structures without staining chromosomes (plate fig. $\mathrm{r}, 2)$. Although the chromosomes were not visible with bright-field or phase-contrast microscopes, stages from prophase to telophase were recognisable by the presence of nucleoli or arrangement of spindle fibres or phragmoplasts. Pre-meiotic interphase and early prophase were identified by comparison of non-hydrolysed sister anthers, longitudinal halves of individual anthers or by relative location of anthers in the spikelet (in Bromus the anthers decrease in age from base to apex of the spikelet). The three anthers in each floret were not always in exactly the same stage of meiosis, but repeated observations allowed the correlation of nuclear body development and stages of early meiosis with reasonable accuracy.

Development of the nuclear body. The development of the nuclear body is shown in fig. $\mathrm{I}, a-m$, which represent microsporocytes or nuclei in stages from pre-meiotic interphase to mid-zygotene. The cell shown in fig. I, $a$ was found in an anther containing some pre-meiotic mitosis and represents very early pre-meiotic interphase. The cell illustrated 
in fig. I, $b$ was obtained from the floret below, and represents a later stage of pre-meiotic interphase. The nuclei of these microsporocytes contained numerous globules of various sizes that appeared to be solid and were dark- or light-staining; there were no globules outside the nuclei. At the beginning of leptotene the globules were not much changed, but in some instances were a little larger than those observed earlier (fig. I, $c, d$ ). As leptotene continued, globules were fewer and some were obviously larger than those present at interphase. Globules were single, dark- or light-staining, and some appeared to be hollow or to have dark-staining rims and light-staining centres (fig. $\mathrm{r}, e, f$ ). At late leptotene globules frequently occurred singly, sometimes in pairs or rarely in an aggregate of three globules, and these often had dark-staining rims and light centres. At the end of leptotene and in early zygotene globules were single or in combinations of two to four (fig. I, $g-l$ ), and probably these small aggregates were more complex. The globules were dark- or light-staining and most had dark rims and light centres. These globules may now be called "nuclear body primordia". The aggregates became larger and fewer, and by midzygotene the nuclear body was generally single, but it often had a double appearance, as if two portions had recently joined (fig. I, $m$; plate fig. I); rarely two parts were separate (fig. I, $n$ ). Rarely there was one large nuclear body and one or two "leftover" primordia (fig. I, o). By late zygotene the nuclear body was single. The darkstaining rims and light centres of the primordia were still visible in the single nuclear body, and it retained this alveolar appearance thereafter.

The globules, nuclear body primordia and aggregates did not appear to be localised in any region of the nucleus or to be associated with the nucleoli. At zygotene the body was found near to or distant from a nucleolus, or in the centre or near the boundary of the nucleus.

At diplotene and diakinesis the nuclear body was single and its former double or aggregate nature was only occasionally visible. A single large nuclear body was present in each microsporocyte at metaphase-I. It was a little smaller at anaphase-I and early telophase-I and considerably smaller at interphase-I and prophase-II. It was sometimes faint-staining at anaphase-II and telophase-II ; occasionally some globules were broken and it appeared to be disintegrating. It was very small or absent in the interphase cells of the quartet.

It was reported previously (Walters, 1963) that the nuclear body was occasionally not visible in the usual acetocarmine preparations of arizonicus and while it was presumed to be hidden under chromosomes the possibility remained that it might not have formed in all microsporocytes. Because the Rattenbury method does not stain the chromosomes, it has now been ascertained that a single nuclear body was present in more than 1250 microsporocytes of arizonicus and absent in none. 

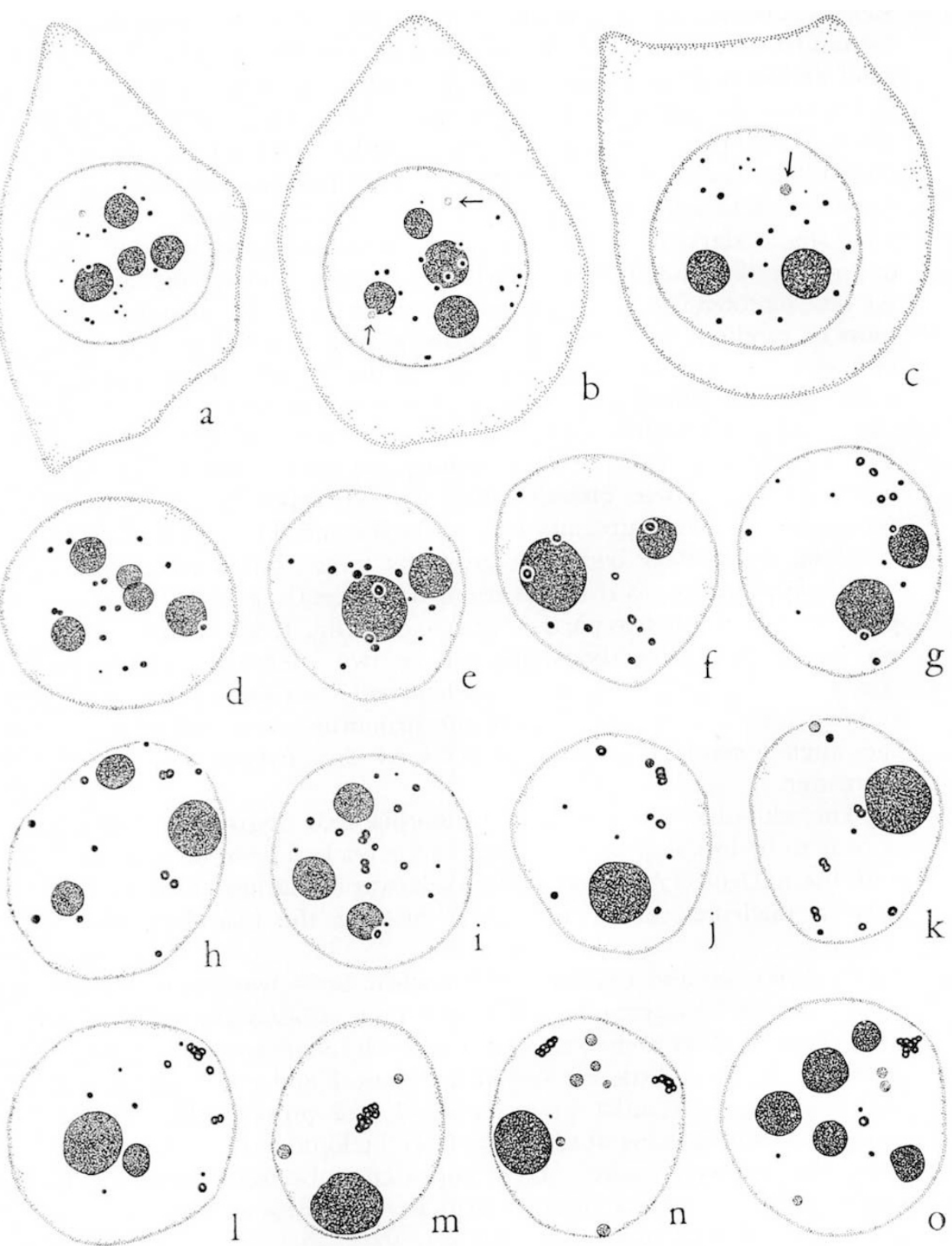

Frg. 1.-a-o. Pollen mother cells from pre-meiotic interphase to zygotene. $\times$ I 000.

a, b. Pre-meiotic interphase; arrow indicates tiny nucleolus bodies.

c-f. Leptotene.

g-l. Late leptotene and early zygotene.

$\mathrm{m}$-o. Zygotene. 
Chemical constitution of the nuclear body. The nuclear body contains. RNA, proteins, and phospholipids. It appears not to contain DNA.

The presence of RNA in the nuclear body was indicated by its staining with pyronin and metachromatic staining with Azure B. The nuclear body was often lighter-staining with pyronin and much lighter-staining with Azure B than the nucleolus at prophase; in later stages it stained with about the same intensity as the spindle and phragmoplast. After ribonuclease digestion the nuclear body did not stain with Azure B, nor was any RNA present in the nucleolus or in the remainder of the cell. The presence of proteins in the nuclear body was indicated by its staining with leuco-basic fuchsin after treatment with alloxan; it was somewhat lighter than the nucleolus. The phospholipid constituent of the nuclear body was indicated by its yellow staining with orange G-aniline blue, and it appeared in this respect to be identical with the nucleolus.

When the Feulgen test was done with whole anthers, 5 minute hydrolysis resulted in intense colouring of chromosomes and no colouring of nuclear body, nucleolus or cytoplasm. With increasing hydrolysis, the chromosomes became less coloured, and nuclear body, nucleolus and cytoplasm exhibited some colour. The nuclear body was not stained in control preparations of non-hydrolysed anthers. When microsporocytes spread on a slide were treated, the intensity of colour of the chromosomes decreased with the increasing length of hydrolysis, but no colour appeared in the nuclear body, nucleolus or cytoplasm. It is therefore assumed that hydrolysis of whole anthers can result in non-specific staining. The nuclear body appeared not to contain DNA.

It was observed that the nuclear body and nucleolus differed in appearance after hydrolysis. The nuclear body was darker than the nucleolus when anthers hydrolysed for I 5 minutes or more were stained in leuco-basic fuchsin. In many preparations the nuclear body was visible under the light microscope when the nucleolus was barely visible under the phase-contrast microscope, and the former was very much darker under phase.

Nucleoli. At pre-meiotic interphase there were I-5 large "principal " nucleoli and sometimes also very small " accessory" nucleoli (Sirlin and Jacob, I962). The number of large nucleoli decreased during interphase and prophase, probably by fusion, and at diakinesis a single large nucleolus remained. During late diakinesis the nucleolus became progressively smaller - but remained round-and it disappeared before metaphase. The small accessory nucleoli were found in all stages from earliest pre-meiotic interphase through diakinesis, but not in all microsporocytes or all anthers. They varied considerably in number and size in individual microsporocytes (fig. $I, b, c, m$; plate fig. I, 2). The smallest of accessory nucleoli may occasionally not have been distinguishable from a nuclear body primordium, but most were considerably larger than the primordia and appeared to be 
homogeneous. During prophase the small nucleoli often appeared to fuse with the principal nucleolus, and none were found at metaphase. While nucleoli were observed to fuse with one another, there was no instance of fusion of nuclear body and nucleolus.

\section{DISCUSSION}

The nuclear body is formed in early prophase of meiosis by aggregation of a number of single globule-primordia. The origin of the primordia is not certain. One possibility is that the tiny globules observed in pre-meitotic interphase increase in size, by fusion and addition of new material, and these finally form the aggregate nuclear body. A second possibility is that these globules disappear during late interphase and early leptotene, while new globules arise and aggregate to form the nuclear body. The second suggestion is consistent with observations in mitosis and meiosis-II; globules are present in interphase preceding pre-meiotic mitosis and in interphase-I, but no structure like the nuclear body is formed from them and they gradually disappear (Walters, unpublished). In either event the nuclear body primordia appear to be formed primarily from materials collected during late pre-meiotic interphase and very early prophase.

Evidence has been presented that the nuclear body contains RNA, proteins and phospholipids, and it appears not to contain DNA. It is probable that the nuclear body primordia have the same composition as the nuclear body.

The nucleolus also contains RNA, proteins and phospholipids (La Cour and Chayen, 1958; Caspersson, et. al., 1963); DNA has not been determined unequivocally to be present or absent but is generally considered to be absent. The similarity in composition suggests that the nuclear body may arise from the nucleolus. Although the location of nuclear body primordia does not indicate any relationship with principal or accessory nucleoli, the possibility exists that sub-microscopic quantities of substances extruded from the nucleoli collect at sites removed from them.

At present it is considered more probable that the nuclear body primordia arise from the chromosomes. The constituents of the nuclear body are present in the chromosomes during the stages when primordia arise. Chromosomes contain RNA and proteins at interphase (Mirsky and Ris, I948; Woods, I959), and lipids are reported in chromosomes during interphase and early prophase (Serra and Seixas, 1962). It has been known for some time that RNA and protein synthesis occur during the first meiotic division (Taylor, I959). Recently peaks of RNA and protein synthesis were observed at leptotene, zygotene and diplotene in Trillium (Hotta and Stern, r963a, b), and continuous RNA synthesis in pre-meiotic as well as early meiotic cells in the grasshopper Melanoplus (Muckenthaler, 1964). In Zea mays RNA is synthesised in pre-meiotic interphase and in meiotic prophase through diakinesis, decreasing as prophase progresses (Das, I965). 
It has been recently demonstrated that chromosomes synthesise RNA throughout first meiotic prophase in orthoptera (Henderson, 1964).

The suggestion that nuclear body primordia arise from the chromosomes is consistent also with their distribution in the nucleus. Globules and primordia are scattered throughout the nucleus when they appear during interphase and leptotene and small aggregates are scattered at early zygotene. Since the chromosomes are spread in the nucleus during these stages, the primordia very probably lie among the chromosomes.

It is interesting to compare the postulated origins of the nuclear body and nucleolus. Nucleoli are believed to form by coalescence of material produced by many regions of the chromosomes (Lafontaine 1958; Sirlin and Jacob, I962; Lafontaine and Chouinard, 1963). The following sequence is observed in sciarid nuclei without organisers (Sirlin and Jacob, I962; Jacob and Sirlin, I963): clusters of ribonucleoprotein particles or "elementary nucleoli" arise within certain bands of salivary chromosomes, grow by apposition of new particles and fuse into larger masses, move to the periphery of the bands and are extruded; sometimes several bodies from nearby bands coalesce and form small free nucleoli. The free nucleolus has a dual structure, with a narrow dense periphery and a broader less dense interior. The authors suggest that in other organisms the elementary nucleoli are brought together by the organiser and form a single large nucleolus. Small accessory nucleoli are visualised as nucleolar material that has not been associated with an organiser. Nuclear body primordia may also be composed of materials collected at a number of sites among the chromosomes. The nuclear body primordium is similar to the "free nucleoli" described above in having a narrow dark-staining periphery and light-staining centre. There appears to be no nuclear body organiser (Walters, 1963 ), and in this respect the primordia are more comparable with accessory than with principal nucleoli. Nuclear body primordia apparently fuse upon contact, as nucleoli do, and the aggregation of nuclear body primordia may be aided by the movement of chromosomes preparatory to their pairing.

The nuclear body and nucleolus are similar in chemical composition and may be similar in origin, but they differ in some significant respects. The nuclear body arises after the nucleolus is formed and in B. arizonicus it persists long after the nucleolus disappears. Differences in composition between the two are indicated by their different responses to certain cytochemical tests and treatments, which have been described above. Further, the nuclear body never fuses with nucleoli, although nucleoli fuse with one another.

The nuclear body may be comparable with structures arising from chromosomes in other organisms which demonstrate "gene action differentially expressed at the level of the chromosome" (Brink, 1964). RNA is given off by various sites of polytene chromosomes, sometimes in the form of small nucleolus-like bodies or "nebennucleoli" that 
are free or connected to RNA-containing bands (Swift, r959). RNA and protein are regularly given off from various sites of lampbrush chromosomes during prophase (Callan and Lloyd, 1960), and puff formation is known to be an expression of specific genes at the sites of the puffs (Beerman, 196r). The nuclear body occurs regularly in meiosis in numerous species of Bromus (Walters, I 963). Furthermore, a nuclear body very similar to that in Bromus has been observed in Zea (Walters, 1965). The structure appears most probably to result from synthetic activities of chromosomes at the onset of meiosis. Whether it is a product of gene action or chromosome reorganisation characteristic of the meiotic division remains to be determined.

\section{SUMMARY}

I. The structure called a nuclear body forms during late leptotene and early zygotene by aggregation of numerous globule-primordia that arise during late pre-meiotic interphase and early leptotene.

2. The body is composed of RNA, proteins and phospholipids but does not appear to contain DNA.

3. It and the nucleolus show similarities and differences in constitution and origin. The nuclear body may arise from the nucleolus but the distribution of body primordia and their development when the chromosomes are synthesising RNA and proteins suggest an origin from the latter.

4. Thus, the body, like puffs and nebennucleoli, may express specific chromosome activity.

Acknowledgments.-I am grateful to Dr Spencer W. Brown, Dr Nirmal K. Das, and Dr James L. Walters for critical reading of the manuscript. I wish to thank Paula A. Piehl for technical assistance in the cytochemical studies.

\section{REFERENCES}

BeERMAN, w. 1961. Ein Balbiani-Ring als Locus einer Speicheldrusen-Mutation. Chromosoma, 12, I-25.

BRINK, R. A. 1964. Genetic repression in multicellular organisms. Amer. Nat., 98, I 93-2II.

GALLAN, H. G., AND LLOYD, L. I960. Lampbrush chromosomes of crested newts Triturus cristatus (Laurenti). Roy. Soc. London Phil. Trans. Ser. B, 243, I35-2 I9.

CASPERsson, T. S., farber, s., foley, G. E., AND killander, D. 1963. Cytochemical observations on the nucleolus-ribosome system. Exper. Cell Res., 32, 529-552.

CONGER, A. D., AND FAIRGHILD, L. M. 1953. A quick-freeze method for making smear slides permanent. Stain Tech., 28, 281-283.

DARLington, C. D., AND LA COUR, L. F. 1962. The handling of chromosomes. $4^{\text {th }}$ edition. G. Allen \& Unwin Ltd., London.

DAS, N. K. I 965 . Inactivation of the nucleolar apparatus during meiotic prophase in corn anthers. Exper. Cell Res., 40, 360-364.

FABERGÉ, A. C. 1945. Snail stomach cytase, a new reagent for plant cytology. Stain Tech., 20, I-4.

FLAX, M. H., AND HIMES, M. H. I952. A microspectrophotometric analysis of metachromatic staining of nucleic acids in tissues. Physiol. Zool., 25, 297-31 I. 


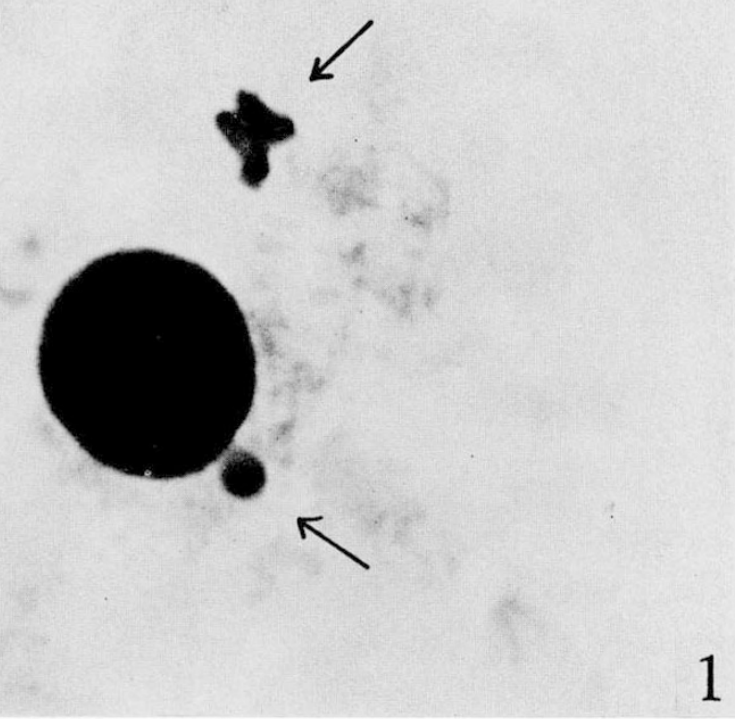

\section{Plate}

FIG. I.-Zygotene showing large nucleolus, nuclear body (upper arrow) and accessory nucleolus (lower arrow). $\times 2900$.

FIG. 2.-Diplotene showing large nucleolus, nuclear body (upper arrow) and accessory nucleolus (lower arrow). $\times 1350$. 
HOTTA, Y., AND STERN, H. 1963a. Inhibitors of protein synthesis during meiosis and its bearing on intracellular regulation. 7. Cell Biol., 16, 259-279.

HOTTA, צ., AND STERN, H. 1963b. Synthesis of messenger-like ribonucleic acid and protein during meiosis in isolated cells of Trillium erectum. 7. Cell Biol., 19, 45-58.

JACOB, J., AND SIRLIN, J. L. I963. Electron microscope studies on salivary gland cells. I. The nucleus of Bradysia mycorum Frey (Sciaridae), with special reference to the nucleolus. F. Cell Biol., $17,153^{-1} 65$.

LA GOUR, L. F., AND CHAYEN, J. 1958. A cyclic staining behaviour of the chromosomes during mitosis and meiosis. Exper. Cell Res., 14, 402-468.

LA COUR, L. F., GHAYEN, J., AND GAHAN, P. S. I958. Evidence for lipid material in chromosomes. Exper. Cell Res., 14, 469-485.

LAFONTAINE, J. G. I958. Structure and mode of formation of the nucleolus in meristematic cells of Vicia faba and Allium cepa. Jour. Biophys. Biochem. Cytol., $4,777-784$.

LAFONTAINE, J. G., AND GHouinard, L. A. 1963. A correlated light and electron microscope study of the nucleolar material during mitosis in Vicia faba. Jour. Cell Biol., 17, 167-201.

MIRSKY, A. E., AND RIS, H. I948. The chemical composition of isolated chromosomes. Jour. Gen. Physiol., 31, 7-18.

MUCKENTHALER, F. A. I964. Autoradiographic study of nucleic acid synthesis during spermatogenesis in the grasshopper, Melanoplus differentialis. Exper. Cell Res., 35, 53 I-547.

RATTENBURY, J. A. I952. Specific staining of nucleolar substance with acetocarmine. Stain Tech., 27, II 3-1 20.

SERRA, J. A., AND SEIXAS, Madalena P. 1962. Distribution of lipids in the chromosomes during mitosis and meiosis. Rev. Portug. Zool. Biol. Ger., 3, 247-254.

SIRLIN, J. L., AND JACOB, J. I962. Function, development and evolution of the nucleolus. Nature, 195, I I4-117.

SWIFT, H. 1959. Studies on nucleolar function. In, A symposium on molecular biology. The University of Chicago Press, Chicago.

TAYLOR, J. H. I959. Autoradiographic studies of nucleic acids and proteins during meiosis in Lilium longiforum. Amer. J. Bot., 46, 477-484.

WALters, marta s. 1963. A nuclear body in meiosis of Bromus. Chromosoma, 14, $423-45$ O.

WALters, MARTA S. 1965. A nuclear body in microsporocytes of Zea mays. Chromosoma, $17,78-84$.

woods, P. s. 1959. RNA in nuclear-cytoplasmic interaction. In, Brookhaven symposia in biology, 12, 153-174.

YASUMA, A., AND ICHIKAWA, T. I953. Ninhydrin-Schiff and alloxan-Schiff staining. A new histochemical staining method for protein. Four. Lab. and Clin. Med., $41,296-299$. 